\title{
TESTEMUNHO E FINGIMENTO: DUAS FORMAS DE ENTENDER A ESCRITA
}

\author{
Madalena Vaz Pinto ${ }^{1}$
}

Recebido: 10/02/2016

Aprovado: 02/06/2016

\begin{abstract}
Resumo: Em duas das poéticas mais marcantes do século XX português - poética do fingimento, de Fernando Pessoa e poética do testemunho, de Jorge de Sena, existe uma diferença na forma de conceber a linguagem: a linguagem como expressão ou a linguagem como criação e devir. No primeiro caso temos o significado precedendo o significante: é a escrita do sentido dado, apreendido. No segundo caso o significante constrói o significado: é a escrita como jogo e invenção. Como tentaremos mostrar, é a partir da análise atenta da poesia de Pessoa que Sena vai construindo a sua e é em oposição à teoria do fingimento que Sena formulará a poética do testemunho. Cabe dizer que Jorge de Sena foi um leitor atento de Pessoa e que faremos referência, em nosso texto, a alguns de seus estudos sobre o poeta, o que, por razões óbvias, não pode ser feito reciprocamente.
\end{abstract}

Palavras-chave: poética; fingimento; testemunho; linguagem; expressão; devir.

\section{TESTIMONY AND PRETENDING: TWO WAYS TO UNDERSTAND THE WRITING}

\begin{abstract}
In two of the most influential poetics of the XXth century in Portugal - Fernando Pessoa "Poetics of Pretense" and Jorge de Sena "Poetics of Testimony" - we find two different conceptions of language: language as expression and language as invention and becoming. In the first case, meaning precedes the signifier: writing is based on a given, already known, signified. In the other one, the signifier produces meaning, writing considered as play and invention. This article wants to underline the differences between them, showing that Sena's poetics is written after a close reading of Pessoa 's and that his Testimony poetics is formulated in opposition to the idea of Pretense found there. As mentioned, Sena was an attentive reader of Pessoa and some of his texts on him will be used in this article. For obvious reasons there are no texts of Pessoa on Sena.
\end{abstract}

Keywords: poetics; pretense; testimony, language, expression, becoming.

O que é curioso observar é o modo como as pessoas se agarram, desesperadamente, à palavra "humanismo", como se fosse a última coisa que quisessem perder.

Eduardo Prado Coelho. "Notas (polémicas) para um anti-humanismo"

Neste texto pretendemos, a partir das noções trazidas por José Gil em Portugal hoje: o medo de existir (2005), pensar a estética do fingimento em seu transbordar da estética para a ética, como um caminho para a invenção de novas formas de vida. A opção pela estética do

\footnotetext{
${ }^{1}$ Professora Doutora na Universidade do Estado do Rio de Janeiro - UERJ / FFP - Faculdade de Formação de Professores
} 


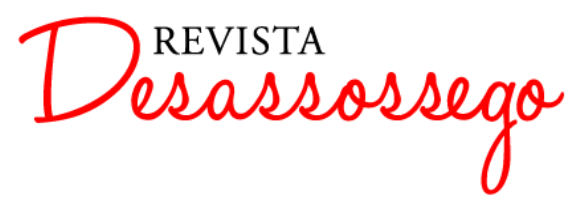

DESASSOSSEGO 15 | JUN/2016 | ISSN 2175-3180

DOI: http://dx.doi.org/10.11606/issn.2175-3180.v8i15p116-126

testemunho - na contramão do fingimento - estaria ligada ao entendimento do texto como expressão do humano e apresentação de uma visão de mundo, mas não apontaria para suas virtualidades.

Um dos problemas que Gil detecta na sociedade portuguesa e que se relaciona com o campo da estética é a ausência de espaço público, um "fora", espaço "neutro", de "ninguém”, um espaço onde, diz Gil, "mais do que um espaço de comunicação, é um lugar de transformação anônima de objetos individuais de expressão" (GIL, 2005, p.28). O que impede essa transformação anônima é o fato da paternidade do texto nunca se desfazer e, por essa razão, o debate em torno da literatura ser sempre "familiarizado, a personalidade social dos interlocutores entrar como uma mais valia de sentido e de verdade do seu discurso" (GIL, 2005, p. 30). Quer dizer que o texto não atinge o "fora”, um lugar "anônimo", que o transforma a ponto de o metamorfosear. E isto acontece porque o texto nunca se autonomiza e adquire vida própria, contribuindo para isso o meio literário que trabalha e alimenta esta personalização do texto e o culto à personalidade do autor. A explicação para a inexistência de um "fora" na sociedade portuguesa pode, segundo o filósofo, ser encontrada na história do país, que passou de forma abrupta de um período de regimes mais ou menos fechados que culminaram em um regime ditatorial, para uma democracia "mediática", sem vivenciar os processos próprios à modernidade. José Gil enumera-os: dessubjetivação ou "morte do homem", a ruptura com a tradição, o descentramento do mundo à volta do homem.

A aproximação entre estas duas poéticas se justifica em primeiro lugar porque Jorge de Sena formula a poética do testemunho distinguindo-a da do fingimento; faz sentido pela influência que Sena teve e tem na poesia portuguesa e, portanto, pela continuidade da poética que formulou; faz sentido por fim porque, em nosso entender, a partir dela é possível pensar a questão da autoria, da relação entre autor empírico e autor textual e a relação texto-leitor, o que nos leva ao encontro da questão da inexistência de um espaço anônimo, como apontado por José Gil.

É no texto "Vinte e cinco anos de Fernando Pessoa", publicado no Estado de S. Paulo em dezembro de 1960, que Jorge de Sena fala da necessidade de ultrapassagem da poesia de Fernando Pessoa. Duas são as justificativas: em primeiro lugar, a necessidade de atualização: "nós não pudemos ficar na obra de um homem que nasceu em 1888 [...] e morreu em 1935; [...]" se a poesia portuguesa persistisse no caminho da poética pessoana, correria perigo, uma vez que, alheia "à transcendência em que [Pessoa criava]" se reduziria 
a praticar "saborosas rendas femininas de verso e de crítica". O caminho, diz Sena, está em, "negando essa transcendência, a transferirmos para a humanidade cujo refazer quotidiano é missão da poesia" (SENA 2000, p. 136). Mas o que Sena chama de transcendência? Ela se relaciona com uma "criação por despersonalização" explicada claramente por Pessoa no apontamento sobre a Estética não aristotélica (PESSOA, 1976, p. 240-246) e na carta a Adolfo Casais Monteiro sobre os heterônimos (PESSOA, 1976, p. 93-99). Esse "processo de criação" não era exclusivo de Pessoa, embora ele seja o seu "mais alto e mais realizado expoente, com suas atitudes insólitas, panfletárias, escandalosas, irónicas" (SENA, 2000, p. 136), que Sena atribui a uma linhagem vinda do esteticismo britânico de raízes nietzschianas. O esteticismo, como o nome indica, enfatiza os temas estéticos em detrimento dos temas sociais e é próximo ao decadentismo e ao simbolismo franceses, presentes na poética de Pessoa pela defesa de uma "filosofia da composição", empenhada na ultrapassagem da subjetividade romântica, representada por Poe-Baudelaire-Rimbaud. Essas estéticas constituíram-se como formas artísticas de aperfeiçoamento espiritual, escuta de uma oculta verdade, elevação da arte a um patamar quase religioso, a uma metafísica, a uma transcendência, termo repetido outras vezes em textos de Sena sobre Pessoa, nomeadamente no texto "O poeta é um fingidor. Nietzsche e outras coisas mais" (SENA, 2000, p. 97). Começando por um fragmento de Nietzsche, "O poeta capaz de mentir/ conscientemente, voluntariamente,/ só ele é capaz de dizer a verdade” (SENA, 2000, p. 98), Sena vai ler esta atitude como construção intelectual presente em Pessoa. Nela, o poeta precisa, para dizer a verdade, de voluntária e conscientemente ser capaz de mentir. Esta mentira não significa nem ficcionalizar nem fingir, mas antes atingir uma verdade não "perturbada pelas circunstâncias factuais da criação" (SENA, 2000, p. 98): a cultura, o ambiente, a educação e a ideologia em que o ato criador se insere. A verdade, em poesia, elimina a oposição verdade-mentira e ocorre no 'ultrapassamento do-em-si' do poeta.

Mas é no prefácio a Poesia I (1961) que Jorge de Sena elabora o conceito de testemunho em oposição a fingimento. Escreve Sena: “a poesia também não é fingimento (o fingimento de Pessoa não é uma arte de iludir, é a acentuação de uma individualidade analítica, de que contemos um mundo de virtualidades e a poesia é uma forma de intensificar aquilo que somos, precariamente)" (SENA, 1961, p. 25). Se Sena reconhece que “o fingimento de Pessoa funcionou em Portugal como uma lição num país em que ser poeta é ser-se "profissional do sentimento" (SENA, 1961, p. 25), distancia-se desta opção ao afirmar: "a parte do artifício, no sentido de técnica de apreensão dessas virtualidades, 


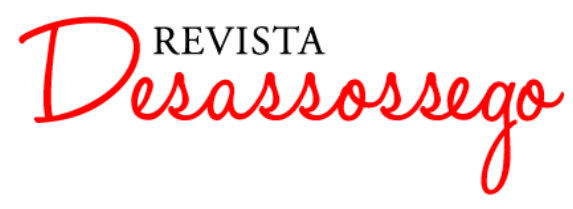

incomodou-me sempre. Porque só artificialmente, em poesia, é possível assumir, exteriormente, a multiplicidade vária que dentro de nós incomoda e é motivo de angústia" (SENA, 1961, p. 25). O que incomoda Sena é o lado "artificial" que a manifestação dessa multiplicidade implica. Não que negue a existência dessa multiplicidade, reconhece-a e reconhece ser ela motivo de angústia. Entretanto, a poesia é uma forma de intensificar aquilo que somos: “[...] creio que a nossa vida humana por de mais precária, por de mais solitária, por de mais intransmissível e única, [...] é tudo o que nos assiste possuir", afirma Sena (1961, p. 25). Gostaríamos de chamar a atenção para esta observação: Sena reconhece o texto pessoano como artifício, e isto é importante porque não enxerga o texto como sintoma, mas como coisa mental, como construção. É um passo enorme, se pensarmos em outros intérpretes, que leem a poesia de Pessoa como movimento de sutura de uma ferida, decorrência da fragmentação do sujeito moderno. Ver-se-á, adiante, que esta leitura tem oscilações, como na entrevista a Luciana Picchio. Acontece que Sena vai identificar no artifício, procedimento que propicia a vivência dessas virtualidades, uma des-coincidência entre estética e ética. A artificialidade inerente à exploração de virtualidades, isto é, a escrita como invenção de situações e de mundos por existir, em oposição à escrita decorrente da experiência, afastam Pessoa, para Sena, de uma postura ética, colocando-a próxima de arte puramente estética, de uma "arte pela arte". Ao definir arte poética, Sena diz: "A arte poética não é, na poesia que se quer verdadeira, mais do que a ciência, melhor ou pior informada, racional ou intuitivamente obtida, de exprimirmo-nos responsavelmente" (SENA, 1961, p. 24).

Começa a ficar clara a diferença entre as duas poéticas: a poesia é expressão responsável, dois termos que remetem para a categoria de sujeito, bem como da linguagem entendida como meio de expressão desse sujeito. São termos que não servem ao entendimento da poesia de Pessoa, "poesia do não-eu", como a denominou Eduardo Lourenço (1972, p.45), e em que a multiplicidade de vozes se choca com a noção de unidade e, portanto, impede a sua vinculação a noções como coerência e responsabilidade, aproximando-se mais de uma ideia de diferença, de jogo e de devir. A linguagem entendida como lugar de invenção e alteridade. Na continuação do mesmo prefácio, ao definir a poesia como processo testemunhal, “[a] melhor arte consistirá em dar expressão ao que o mundo (o dentro e o fora) nos vai revelando, não apenas de outros mundos simultânea e idealmente possíveis, mas, principalmente, de outros que a nossa vontade de dignidade humana deseja convocar" (SENA, 1961, p. 26), Sena atribui à poesia um papel 
transformador, "porque através dele se remodela os esquemas feitos, ideias aceites, hábitos sociais, convenções” (SENA, 1961, p. 25).

Se Sena reconhece no fingimento pessoano "sem dúvida, a mais alta forma de educação, libertação e esclarecimento do espírito enquanto educador de si próprio e dos outros" (SENA, 1961, p. 26), afirma haver aí "muito de orgulho desmedido", contrastante, por sua vez, com "a humildade expectante, a atenção discreta, a disponibilidade vigilante" (SENA, 1961, p. 25) próprias da poética do testemunho. Quando compara orgulho desmedido com humildade expectante, Sena faz um julgamento moral, não estético, ao mesmo tempo em que reivindica para a poesia um engajamento, uma tomada de posição frente aos acontecimentos do mundo. Para Sena, a linguagem é meio de expressão do sujeito poeta, sujeito este que, se se constrói outro a cada poema, permanece bastante próximo ao eu-empírico, o que parece ficar evidente pelos termos usados por Sena como fundamento de sua poética: responsabilidade e dignidade humanas, uma imagem que remete para um humanismo intocado, não conciliável, portanto, com as coordenadas de uma modernidade tal como formulada por José Gil, assente na dessubjetivação, ruptura com a tradição e descentramento do mundo à volta do homem.

É possível depreender destas afirmações um tom, entre a admiração e irritação, presente em muitos outros textos de Sena sobre Pessoa, entre eles aquele em que afirma: "Fernando Pessoa sabia perfeitamente (e desde cedo na vida) que, apesar do génio de um ou outro dos seus amigos e companheiros, e de alguns outros na geração seguinte, a primeira metade do século XX, em poesia escrita em português, seria sua, para lá da grandeza que lhe daria um lugar muito próximo de Camões na História literária” (SENA, 2000, p. 357-358). A leitura que Sena faz da poética do fingimento, e a formulação da poética do testemunho em oposição a ela, é também, como fica evidente, a busca por um lugar de reconhecimento dentro do campo literário português.

Em uma entrevista dada a Luciana Stegagno Picchio em 1977, Sena insere então o "fingimento" pessoano na poética moderna, presente em outros poetas que queriam romper com a subjetividade romântica. As raízes desse conceito poderiam ser encontradas na mímesis aristotélica uma vez que, ao contrário da mímesis platónica, que considerava a poesia uma imitação de segundo grau, a imitação da imitação, Aristóteles dá ao poeta a possibilidade de fingir a realidade. A poesia é então valorizada, mais valorizada que a história, porque se o historiador escreve o que aconteceu, o poeta imagina o que poderia acontecer, o que pressupõe um conhecimento superior, o da natureza humana. A poesia é 


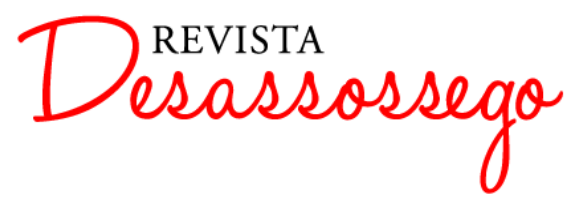

DESASSOSSEGO 15 | JUN/2016 | ISSN 2175-3180

DOI: http://dx.doi.org/10.11606/issn.2175-3180.v8i15p116-126

por essa razão algo de mais filosófico e mais sério que a história, já que se refere ao universal, enquanto a história se refere ao particular. E completa Sena: "sem esse fingimento a criação estética não é possível” (SENA, 2000, p. 342). Se o fingimento é legitimado pela própria estética aristotélica, é preciso notar que o fingimento de Pessoa dela se afasta, como esclarece o poeta nos "Apontamentos para uma estética não aristotélica" (PESSOA, 1976, p. 240), descrevendo o fingimento heteronímico como de um grau superior, só possível, como aponta Sena, mediante o recurso à artificialidade. Mas a que se pode opor o artifício? Fazenda Lourenço, autor de Testemunho, metamorfose, peregrinação, sobre a poesia de Jorge de Sena, define assim a poética do testemunho: “A concepção da poesia como testemunho, $[\ldots]$ requer $[. .$.$] do poeta uma competência especial, o exercício de uma$ faculdade específica: a de ser escuta e voz do mundo" (LOURENÇO, 1998, p. 63).

Escuta e voz do mundo. De fato, se pensarmos na poesia de Fernando Pessoa, percebemos que estamos diante de uma poesia que mais que escutar o mundo, inventa mundos. A heteronímia não fala de experiências, inventa-as. Nesta defesa da poesia como testemunho em contraponto à poesia como artifício, têm-se claramente duas concepções de literatura: a literatura que inventa e a literatura que testemunha. A literatura como possibilidade de devir e a literatura como testemunho do vivido. Têm-se ainda uma escrita "para além do bem e do mal" e uma escrita que clama para si um valor moral. Sena sabe que escrever nunca é escrever o que se "quer", que o escrito não coincide com o que quis escrever. Existe, portanto, na poética do testemunho, essa noção de uma alteridade intrínseca à linguagem. Entretanto, o poeta tem a responsabilidade de testemunhar o mundo em que vive e só pode fazê-lo, sendo poeta, pela linguagem. Sena reconhece a alteridade da linguagem sem colocar em causa seus fundamentos, o que nos interessa para pensar a relação entre linguagem e humanismo. A concepção da poética do testemunho é do testemunho enquanto criação de linguagem: o testemunho, enquanto poética transformadora de mundo é, antes de mais, linguagem.

Ora, foi exatamente a colocação da linguagem sobre suspeita a ignição para a poesia do fingimento. A suspeita perante a linguagem, sua desnaturalização, foi o passo inicial para a crítica contundente feita à cultura ocidental e à ideia de homem em que assentava, começada por Nietzsche e continuada pela filosofia pós-metafísica. Trata-se de contestar as bases em que esta cultura se fundara: metafísica, logocentrismo, verdade, em última análise, uma certa imagem de homem. Foi o que Eduardo Lourenço entendeu na poesia de Fernando Pessoa: 


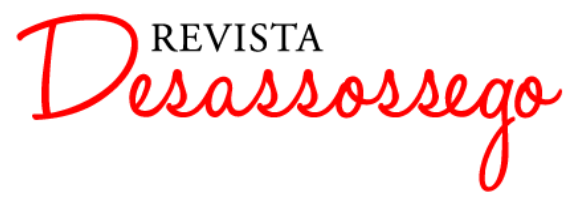

DESASSOSSEGO 15 | JUN/2016 | ISSN 2175-3180

DOI: http://dx.doi.org/10.11606/issn.2175-3180.v8i15p116-126

o que Pessoa compreendeu, antecipando-se a formulações futuras e óbvias, foi que essa morte de Deus era, ao mesmo tempo, como ensinava entre equívocos Frederico Nietzsche, morte do bomem, fim da ilusão humanista que imaginava ainda poder justificar, na perspectiva de uma ausência de Sentido transcendente para o universo e para a História, os mesmo valores, as mesmas ilusões consoladoras, a mesma moral tranquilizante (LOURENÇO, 1986, p. 14, grifo do autor).

Para Eduardo Lourenço, a obra de Pessoa é, justamente, uma tentativa de sutura desse mundo sem Deus:

Nenhum poeta da Modernidade exprimiu como Pessoa esta absoluta perdição do sentido do nosso destino enquanto mundo moderno e isto bastaria para que o autor da Tabacaria se tivesse convertido não apenas no mito que é para nós, mas também numa das referências-chaves da Cultura contemporânea (LOURENÇO, 1986, p. 12)

e nisso, difere absolutamente da leitura de José Gil, para quem sua poesia é, sobretudo, intensificadora da vida: "Uma ideia estranha veio então instalar-se em boa parte de exegese pessoana: a ideia de que Fernando Pessoa construiu toda a sua obra em torno de uma negação fundamental da vida" (GIL, 2005, p. 247-8).

Eduardo Prado Coelho, no ensaio "Notas (polêmicas) para um 'anti-humanismo”, (1967) escrevia:

Assim como o humanismo no sentido de hoje é invenção do séc. XIX, o antihumanismo tem em Nietzsche um de seus inequívocos representantes. Seria lícito falar de humanismos, se o humanismo incluísse nele as diferenças existentes no mundo dos homens. Mas é exatamente a isso que o humanismo se recusa, por se colocar como universal, acima das diferenças e aí adquirir um papel mistificador (PRADO COELHO, 1972, p. 34).

É em relação a este humanismo que se propõe um anti-humanismo. Mas é preciso entender que o pensamento anti-humanista, a partir do qual se desenvolve a poética moderna, não é contra o homem, mas por um outro homem: um homem sem deus, ciente da contingência de seus valores. Eduardo Prado Coelho retoma então uma pergunta feita por Blanchot em “O ateísmo e a escrita, o humanismo e o grito" (2007 p. 247): será possível o ateísmo? Porque a morte de Deus afinal não se dá se o homem interiorizou os seus poderes, visíveis nas formas de um conhecimento que se apresenta como "luz", como evidência. Esta atitude logocêntrica tem como base o signo transcendental de que nos fala Derrida. Assim usado, como instrumento que exprime um sentido dado, e por um sujeito em posição privilegiada, o ateísmo é impossível. Não se anula Deus transpondo para "dentro" do homem um projeto teleológico no sentido de superação, progresso e, ao mesmo tempo, de exclusão do que não cabe nessa ideia de universalidade. Só se poderia 
começar a pensar em ateísmo, em um novo-humanismo, se uma outra dimensão fosse aberta, na qual o homem e sua razão abdicassem de seu lugar de absoluto. A perda da ideia de centro, continua Derrida, é "a ausência de um significado transcendental, amplia indefinidamente o campo e o jogo da significação" (DERRIDA, 2002, p. 232); não havendo centro ou origem, tudo se converte em discurso. Por outro lado, uma vez que não é possível abandonar os conceitos da metafísica, já que não se dispõe de uma outra linguagem, de nenhum outro léxico ou de nenhuma outra sintaxe que possa se colocar fora dessa história, "a linguagem carrega em si a necessidade de sua própria crítica" (DERRIDA, 2002, p. 237). O discurso humanista seria exatamente aquele a salvo dessa crítica, para o qual não se coloca a questão da linguagem. "Uma atitude humanista" diz Prado Coelho, "habituou-nos a pensar que os significados precedem os significantes, e que a linguagem falada precede a linguagem escrita”. Mas

se o significante é sempre a representação material de um significado, recuando progressivamente, teremos de considerar um momento original em que existe o significado sem que ainda exista o significante. Este significado transcendental só pode ter um sentido teleológico (COELHO, 1972, p. 40).

O que uma atitude anti-humanista irá fazer é inverter esta situação: a escrita não exprime algo que a anteceda, ela cria aquilo que exprime.

Nietzsche tem neste processo de desmistificação da linguagem um papel fundamental, ao apresentar a sua versão sobre a constituição da linguagem e arbitrariedade das línguas no texto: "A verdade e mentira no sentido extra-moral":

As diferentes línguas, colocadas lado a lado, mostram que nas palavras nunca importa a verdade, nunca uma expressão adequada: pois senão não haveria tantas línguas. "A coisa em si" (tal seria justamente a verdade pura sem consequências) é, também para o formador da linguagem, inteiramente incaptável e nem sequer algo que vale a pena. Ele designa apenas as relações das coisas aos homens e toma em auxílio para exprimi-las as mais audaciosas metáforas (NIETZSCHE, 1999, p. 55).

O que é a verdade, portanto? Um batalhão móvel de metáforas, metonímias, antropomorfismos, enfim, uma soma de relações humanas, que foram enfatizadas poética e retoricamente, transpostas, enfeitadas, e que, após longo uso, parecem a um povo sólidas, canônicas e obrigatórias: as verdades são ilusões, das quais se esqueceu que o são, metáforas que se tornaram gastas e sem força sensível, moedas que perderam sua efígie e agora só entram em consideração como metal, não mais como moedas (NIETZSCHE, 1999, 57). 
Para Nietzsche, tratava-se de mostrar a relação existente entre linguagem e poder, poder e moral. Porque o poder se exerce alegando um valor de verdade. Ao eleger a arte como a mais importante atividade do homem, Nietzsche defende o seu valor de aparência, de máscara, de interpretação, contra o suposto valor de verdade da ciência e da moral. A arte é mais verdadeira porque desde logo se assume como aparência, sem pretensão de dar uma interpretação "verdadeira".

No período em que Sena começa a escrever, década de 30-40, convivem então, em Portugal, correntes simbolistas e pós-simbolistas, e inicia-se a divulgação, pela revista Presença, dos textos do modernismo, através da publicação de inéditos de Mário de SáCarneiro e de Fernando Pessoa, cujas obras só começariam a ser publicadas em 1942. No final da década de 30, o panorama era de homogeneização da cultura e literatura portuguesas em torno do movimento doutrinário do neorrealismo (o surrealismo, surgido no final de década de 40, embora se lhe opusesse frontalmente, não abalou sua hegemonia). O aparecimento de grande parte dos poetas nos anos 30 dá-se, assim, durante um período traumático da vida portuguesa, a seguir ao golpe militar de 1926 e à instauração do Estado Novo, em 1933, com o agravante da eclosão de dois grandes conflitos: guerra civil espanhola, 1936-1939, e a segunda guerra mundial, 1939-1945. O ambiente de controle por parte da censura e a radicalização da vigilância policial tornavam impraticável a troca de ideias e o livre pensamento, situação muito diferente daquela em que surgiu o movimento saudosista e, em decorrência, a primeira geração modernista.

Jorge de Sena posiciona-se frente ao duplo patrulhamento então vivido pelos escritores independentes, denunciando a situação perversa de poetas próximos esteticamente serem julgados por suas ideias e preferências políticas e não por suas obras. Se Sena se considerava próximo às preocupações sociais dos neorrealistas, afastava-se da forma simplista como se desenvolvia, nesse movimento, a relação entre prática literária e intervenção na realidade (LOURENÇO, 1998, p. 31-32). É provável que se tenha instituído neste momento um traço ainda persistente na literatura portuguesa: referimo-nos à necessidade da defesa de uma ética por parte dos escritores portugueses, sustentada pela proximidade entre sujeito autoral e sujeito empírico, posição essa da qual não nos parece que Sena esteja longe. Quando diferencia a poética do testemunho da poética do fingimento e afirma: "porque só artificialmente, embora no plano da poesia e não no das artes distractivas, nos é possível assumir extrinsecamente, exteriormente, a multiplicidade vária, que dentro de nós, é uma família incómoda", e relaciona tal poética com a 
acentuação de uma "individualidade eminentemente analítica" (SENA, 1960, p. 25), Sena não atenta para dois aspetos fundamentais: o devir e a relação de exterioridade que por sua vez a arte implica. A arte implica um devir outro: para se sentir artisticamente, pelo outro, é preciso que o eu perca seus contornos precisos A arte intensifica a vida, desautomatiza a percepção, faz sentir melhor aquilo que a vida, no seu cotidiano de gestos automáticos e apressados, não permite fazer. Reconhecer que a linguagem é destituída do valor de verdade não significa que ela seja destituída da possibilidade de afetar e intervir no mundo, o que dependerá de sua força poética.

Não se trata, portanto, de mudar o mundo pela arte. Essa não parece ser uma boa formulação, uma vez que não se produz aí uma relação direta entre criador e criado, como se os efeitos produzidos pela arte derivassem de uma prévia "intenção" autoral e não de sua força poética. Imbuir-se dessa tarefa seria considerar-se passível de sabedoria para fazêlo, e a arte o resultado de uma ideia prévia. Todavia, o que se pode esperar da arte é que aumente as capacidades de sentir, de ver, de inventar mundos possíveis, que produza linhas de fuga em relação ao mundo existente.

Os textos de Jorge de Sena, que os paratextos reforçam, estão impregnados de uma presença autoral insubstituível. Até que ponto isto tem influenciado sua recepção? Voltando ao princípio da nossa argumentação com base em José Gil: será que a paternidade nos textos de Sena contribui para a sua metamorfose ou, pelo contrário, impede que esta se dê, em função de uma interpretação excessivamente colada na figura de seu autor? É possível ler Sena sem remeter para o sujeito empírico?

"Dar a iniciativa às palavras" é deixá-las livres de uma voz mandatária. A dessubjetivação, não leva necessariamente à intransitividade, e talvez seja esta a maior diferença entre Deleuze e Foucault. A linguagem literária está sempre relacionada com um "fora", ela sempre se relaciona com um elemento não-linguístico, embora esse campo de relações não esteja no controle do autor determinar. $\mathrm{O}$ apagamento do autor no escrito é o modo de despaternalizar o texto, deixando-o livre para captar devires e subjetividades que não estão em seu controle determinar. Em Fernando Pessoa, essa paternidade é intencionalmente baralhada, jogada ironicamente. A inovação da poética do fingimento de Fernando Pessoa é justamente a criação de uma multiplicidade de vozes e o descentramento do sujeito que essa escrita implica e evidencia. O erro é relacionar tal poética com uma espécie de solipsismo. 
Não se trata de negar a legitimidade de uma poética que parta de uma volta à percepção do mundo pelo sujeito, uma espécie de volta às coisas mesmas olhadas do ponto de vista de quem as experimenta. O que é mais difícil de entender é que nessa opção se opere uma espécie de "regresso", de suspensão da história, de retorno aos elementos constitutivos da metafísica, postos em xeque pela modernidade, onde se incluem a morte de deus, o abalo do sujeito cartesiano, a necessidade de repensar os fundamentos do conhecimento, a ruptura com a tradição. Nesse hiato de sentido, neste intervalo entre o passado e o futuro, a linguagem pode se assumir enquanto invenção de novas formas de vida.

\section{Bibliografia}

BLANCHOT, Maurice. A conversa infinita. A experiência limite. Trad. João Moura Jr. São Paulo: Escuta, 2007.

COELHO, Eduardo Prado. O reino flutuante. Exercícios sobre a razão e o discurso. Lisboa: Edições 70, 1972.

DERRIDA, Jacques. “A estrutura, o signo e o jogo no discurso das ciências humanas". In: A escritura e a diferença. São Paulo: Perspectiva, 2002.

GIL, José. A metafísica das sensações. Trad. Miguel Serras Pereira e Ana Luísa Faria. Lisboa, Relógio d 'Água, s.d.. . Portugal hoje: o medo de existir. Lisboa: Relógio d 'Água, 2005.

LOURENÇO, Eduardo. Pessoa revisitado. Porto: Inova, 1973. Fernando, rei da nossa Baviera. Lisboa: INCM, 1986.

LOURENÇO, Jorge Fazenda. Testemunho, metamorfose, peregrinação. Paris: Centre Culturel Calouste Gulbenkian, 1998.

MORNA, Fátima Freitas. Poesia de Jorge de Sena. Apresentação crítica e seleção. Lisboa: Editorial Comunicação, 1985.

NIETZSCHE, Friedrich. "Sobre verdade e mentira no sentido extra-moral". In: Os pensadores. Trad. Rubens Rodrigues Torres Figueiredo. São Paulo: Nova cultural, 1999.

PESSOA, Fernando. Obras em prosa. Rio de Janeiro: Nova Aguilar, 1976.

SENA, Jorge de. Fernando Pessoa e Ca. Heteronima. (Estudos coligidos 1940-1978). Lisboa: Edições 70, 2000. . Poesia I. Lisboa: Moraes editora, 1961. 